\title{
Om forskningsstödjande tjänster för forskningsdata i UH-bibliotek
}

\author{
Best practice article \\ Karin Rydving* \\ Universitetet i Bergen
}

\begin{abstract}
This article presents data collected from a survey among the library directors of the 32 members of the UHR Library. The survey found that most academic libraries are currently offering or are planning to offer various consultative RDS, rather than technical or hands-on RDS. The majority of academic libraries provide support for training in skills related to RDS for their library staff. Almost all libraries collaborate with other units inside their institutions, or with outside institutions. The libraries reported they had or are planning to reassign existing staff to provide RDS. The library directors mainly agree on the importance of RDS among the academic libraries. This indicates that academic libraries want to continue to expand their responsibility within RDS through collaboration, and existing library staff.
\end{abstract}

Keywords: Academic libraries, research data services, library skills, collaboration 


\section{Inledning}

Kraven på öppen tillgång till forskningsinformation har ökat under senare år, vilket inte minst avspeglas i forskningspolitiska riktlinjer på nationell och internationell nivå. Målet är att öka forskningens transparens, användbarhet och tillgänglighet (Forskningsrådet, 2017; 2020; Kunnskapsdepartementet, 2017). Man förväntar i högre grad att lärosätena utarbetar interna rutiner, processer och kurser för datahanteringsplaner, arkivering och tillgängliggöring av forskningsdata. Dessa tjänster bör framför allt fokusera på funktioner som fungerar som stöd till forskare, och vara i samklang med överordnade nationella och internationella riktlinjer. Forskningsdatatjänster beskrivs som ett omfattande fält, där biblioteket pekas på som en av flera aktörer för att utveckla ett adekvat stöd till forskningen och forskarna (Cox, Pinfield \& Smith, 2014; Linde, Noorman, Wessels \& Sveinsdottir, 2014).

I denna artikel vill jag kort presentera status och planer för forskningsstödjande tjänster för forskningsdata i norska universitets- och högskolebibliotek (UH-bibliotek). När jag skriver bibliotek eller UH-bibliotek avser jag universitets- och högskolebibliotek. Artikeln tar även upp hur biblioteken hanterar kompetens- och samarbetsfrågor rörande forskningsdatahantering, och vilken inställning ledare i UH-bibliotek har till forskningsdatatjänster. Jag reflekterar också över vilka kompetensfält som biblioteket kan behöva täcka för att erbjuda forskningsdatatjänster. Artikeln är baserad på min tidigare studie (Rydving, 2019a) och artikel (Rydving, 2019b).

\section{Bakgrund}

Wilson, Martinez-Uribe, Fraser och Jeffreys (2011, s. 285) menar att två principer är avgörande för att utveckla relevanta och hållbara forskningsdatatjänster vid en forskningsinstitution. Den första är att forskarnas behov måste stå i centrum. Den andra är nödvändigheten av att samordna olika avdelningars tjänster så att forskarmiljöerna upplever ett sammanhängande och effektivt stöd. En institutionell insikt om att det inte bara är en avdelning som ensam har ansvar för att utforma forskningsdatatjänster bör prägla utvecklingen (Wilson et al., 2011). Tjänsteutvecklingen sker i en omgivning där de ekonomiska resurserna är begränsade, tiden upplevs som knapp och intressenterna kivas om att positionera sig (Cox et al., 2014; Tenopir et al., 2017).

Tidigare studier om forskares behov pekar på en efterfrågan av matnyttiga tjänster för hantering av data, och att utbudet gärna bör integreras i redan pågående verksamhet (Corrall, 2012; Fransson, du Toit, Tapia Lagunas \& Kjellberg, 2016; Wilson, Martinez-Uribe, Fraser \& Jeffreys, 2011). Det krävs tillräckliga kunskaper och förtroende hos användarna om biblioteket vill utvidga sitt undervisningsdomän från traditionell informationskompetens till en mer datakunskapsorienterad profil. För att uppnå den positionen kan biblioteket ha behov av att förbättra sina tekniska färdigheter och ämnesspecifika kunskaper, eller satsa på samarbeten (Frank \& Pharo, 2016).

Flera författare diskuterar arbetet med forskningsstödjande tjänster inom ramen av ett "wicked problem" (Cox et al., 2014; Tenopir et al., 2017). Det erkänns som en omfattande uppgift att manövrera existerande tjänster och nya behov av tjänste- och kompetensutveckling 
i biblioteket (Tenopir et al., 2015). Forskningsdatatemat är så omfattande och mångfasetterat vad gäller infrastruktur, förväntade färdigheter och intressenter att biblioteket på inget sätt kan lösa uppgiften på egen hand (Corrall, 2012; Lewis, 2010). Biblioteket, forskningsadministrativ avdelning och IT-avdelningen pekas på som samarbetspartner för att utveckla och underhålla helhetliga tjänster som stöd för forskarmiljöerna (Corrall, 2012; Strasser \& Krier, 2014; Tenopir, Birch \& Allard, 2012; Wilson et al., 2011).

Temat forskningsdata kan tyckas svårmanövrerat, men den dominerande synen är dock att forskningsdatafältet utpekas som ett växtområde. Biblioteket bör utvidga sin roll, och utveckla området till ett huvudelement i sitt uppdrag för att stödja forskningsmiljöerna (Corrall, 2012; Lewis, 2010; Linde et al., 2014; Tenopir et al., 2012; Tenopir et al., 2017). Även om forskningsdatatjänster kan verka främmande hävdar flera studier att det finns starka kopplingar mellan dagens biblioteksutbud och nya tjänster för forskningsdatahantering (Corrall, 2012; Tenopir, Sandusky, Allard \& Birch, 2013). Att bidra till en öppen vetenskap kan ses på som en naturlig förlängning av bibliotekens långvariga engagemang för öppen tillgång (Corrall, 2012, s. 108). I egenskap av sin roll som en etablerad kunskapsorganisatör har biblioteket en uppgift att också hantera och ge tillgång till forskningsdata. Det vill i sin tur bidra till att öka synligheten av institutionens forskning (Corrall, 2012; Fransson et al., 2016; Lewis, 2010; Linde et al, 2014). Med framväxten av det digitala biblioteket är det allt färre forskare som använder det fysiska biblioteket. Stödtjänster för forskningsdata kan vara den länk som biblioteket behöver för att återknyta sin kontakt med forskningsmiljöer och styrka sin position (Corrall, 2012; Lewis, 2010).

Hur bibliotek vid forskningsinstitutioner förhåller sig till forskningsdatatjänster undersöks bl. a. i Tenopir et al. (2017). I en frågeundersökning som besvarades av 119 biblioteksledare från 22 europeiska länder med en svarprocent på 35,7 \% visar resultaten att rådgivande forskningsstödjande tjänster är vanligare än tekniskt orienterade. Konsulterande funktioner på campus är den vanligast förekommande tjänsten, följd av arbete med policyfrågor och kursverksamhet. Av de tekniska tjänsterna är hanteringsstöd vad gäller t. ex. arkivering och tillgångar vanligast. Huvudparten av respondenterna samarbetar i någon form med enheter, inom eller utanför den egna institutionen, för att utveckla tjänster och riktlinjer relaterade till forskningsdata. De flesta av biblioteksledarna stödjer att befintlig personal styrker sin kunskap inom fältet. Majoriteten av de svarande biblioteken anser att forskningsstödjande tjänster för forskningsdata är ett relevant område för bibliotekets utveckling.

\section{Metod}

För att undersöka status och planer angående forskningsdatatjänster vid norska bibliotek genomförde jag hösten 2018 en enkät som omfattade 17 frågor (Rydving, 2019a). Frågeschemat var i princip sammanfallande med Tenopir et al. (2017). Enkäten var på engelska och bestod av 2 inledande kategoriseringsfrågor, så följde 14 stycken kunskapsfrågor och slutligen en fråga där respondenten skulle uppgegraden av enighet (Johannessen, Tufte \& Christoffersen, 2016). Enkäten skickades till biblioteksledarna vid de bibliotek som är medlemmar i Universitets- og høgskolerådets strategiska enhet bibliotek (UHR-Bibliotek). I denna enhet ingår bibliotek från 
10 universitet, 9 vetenskapliga högskolor, och 13 högskolor. Deltagandet var frivilligt och anonymt. Det var också frivilligt att välja att besvara en fråga, med undantag av kategoriseringsfrågorna.

Totalt svarade 19 institutioner av 32 inbjudna (svarsprocent 59 \%) på enkäten. Den övervägande andelen av svaren kom från institutioner med fler än 5000 studenter. Det största bortfallet kunde kopplas till institutioner med färre än 2000 studenter. Det är alltså en skevhet i mina insamlade data. Det kan tyda på att institutioner som redan har ett intresse för fältet också är de som har svarat. Jag presenterar här ett urval av studiens resultat.

\section{Resultat}

Resultatet tyder på att forskningsstödjande tjänster för forskningsdata är ett etablerat tjänsteutbud bland UH-biblioteken. Det är bibliotek vid lärosäten med fler än 5000 studenter som erbjuder flest tjänster och som har de mest ambitiösa utvecklingsplanerna.

Vad gäller utbudet av forskningsdatatjänster kunde respondenterna välja att ange status och eventuella planer för 14 olika definierade tjänster. Dessa kan delas upp i rådgivningstjänster (figur 1) och tekniskt orienterade tjänster (figur 2). Svaren visade att 14 av de 19 (74\%) biblioteken erbjuder minst en tjänst idag, och ytterligare 4 bibliotek har planer om att starta ett utbud. Det är 4 av biblioteken som erbjuder fler än 10 stycken av de 14 undersökta tjänsterna, och ytterligare 7 bibliotek som har planer om att också göra detsamma. Min undersökning säger dock ingenting om vilka tjänster som eventuellt måste ge vika för att följa upp växtplanerna för forskningsdataområdet. Vilken inställning bibliotekspersonalen har till forskningsdatatjänster granskas inte heller i undersökningen.

Figur 1 visar att de mest förekommande tjänsterna är dialogbaserade och rådgivande. I gruppen rådgivningstjänster är den vanligaste tjänsten deltagelse $\mathrm{i}$ arbete med policy- och strategidokument, följt av dialogbaserade tjänster med kolleger på biblioteket, inom eller utom institutionen. Av de tekniskt orienterade tjänsterna (figur 2) är den vanligaste tjänsten hanteringsstöd kopplat till arkiv, informationssök och tillgång, följt av metadatahantering och tillrättaläggning av datasett för arkivering. 
Involved in either policy development or strategic planning related to research data services (RDS)

Discussing research data services (RDS) with other librarians, or other people on campus, or RDS...

Outreach and collaboration with other research data services (RDS) providers either on or off campus

Directly participating with researchers on a project (as a team member)

Training colleagues in your library, or across campus, on research data services (RDS)

Creating web guides and finding aids for data / data sets / data repositories

Consulting with academic staff or students on data management plans

Providing support for finding and citing data/data sets

$0 \%$

No, but plan to within the next 12 months

- Yes, our library currently offers this service

No, but plan to within 13-24 months

No, but plan to do so in more than 24 months

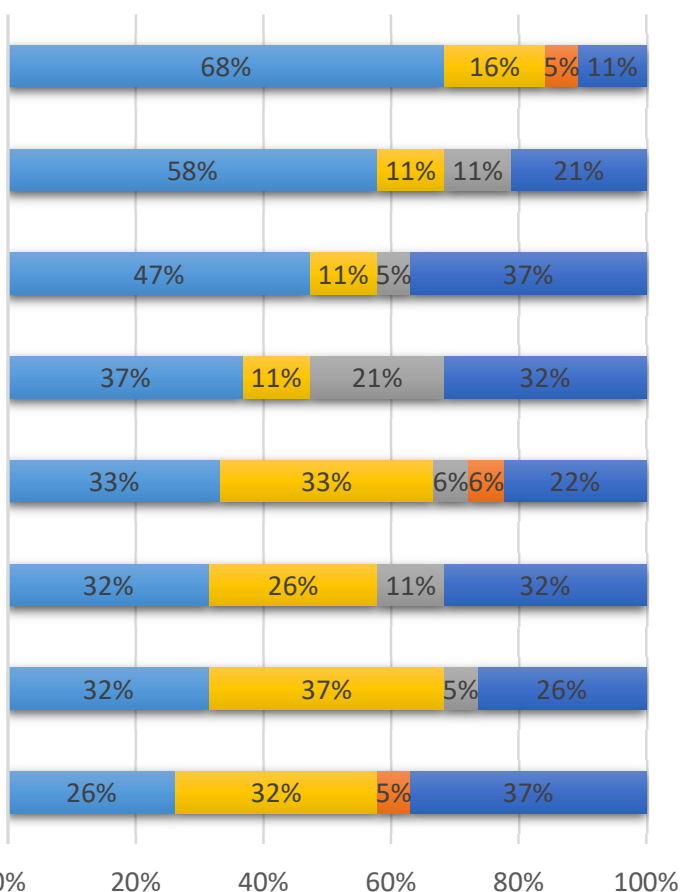

$100 \%$

No, and we currently have no plans to do so

Figur 1. Consultative research data services (RDS), n=264 (Rydving, 2019a).

Providing technical support for research data services (RDS) systems (e.g., a repository, access and discovery systems)

Creating or transforming metadata for data or data sets

Preparing data / data sets for deposit into a repository

Deaccessioning/deselection of data / data sets for removal from a repository

Identifying data / data sets that could be candidates for repositories on or off campus

Selection of data / data sets for repository

$0 \%$

Yes, our library currently offers this service

No, but plan to within 13-24 months

No, and we currently have no plans to do so

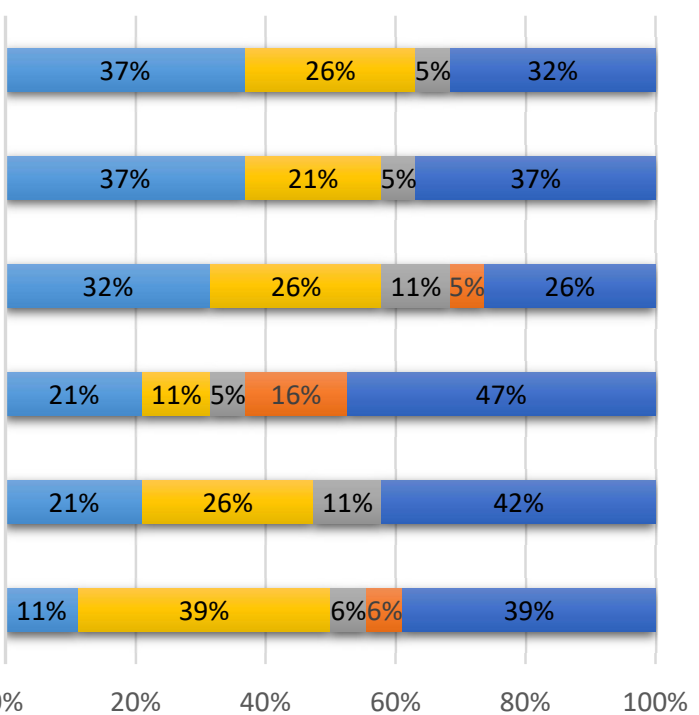

No, but plan to within the next 12 months

No, but plan to do so in more than 24 months

Figur 2. Technical research data services (RDS), n=264 (Rydving, 2019a). 
Det är också inom förebyggande rådgivningstjänster som flest bibliotek har planer om att utvidga sitt tjänsteutbud. De tjänster som biblioteken i minst utsträckning planerar att etablera är av teknisk art, och kopplade till förvaltning och underhåll av datasett i arkiv. En teknisk klassificerad stödtjänst för hantering och förberedelse av datasett för lagring är emellertid högst prioriterad att kunna erbjuda, därefter dialogorienterade tjänster om datahanteringsplaner, kursverksamhet och informationssök.

En övervikt av respondenterna, 15 av 18 bibliotek (83\%) uppgav att de har erbjudit bibliotekspersonalen kompetensutveckling inom forskningsdatafältet. För att hantera kapacitetsbehovet av personal med kunskap inom forskningsdatatjänster visar figur 3 att biblioteken använder sig av flera strategier. Vad gäller valet mellan att rekrytera eller att satsa på existerande personal uppgav en majoritet (12 stycken, $75 \%$ ) att de redan har omplacerat personal, och/eller planerar (10 stycken, 63 \%) att göra (ytterligare) ändringar. Ett fåtal bibliotek svarade att de har planer på att rekrytera ny personal, eller uppgav att de rekryterat dedikerad personal för att arbeta med forskningsdatatjänster.

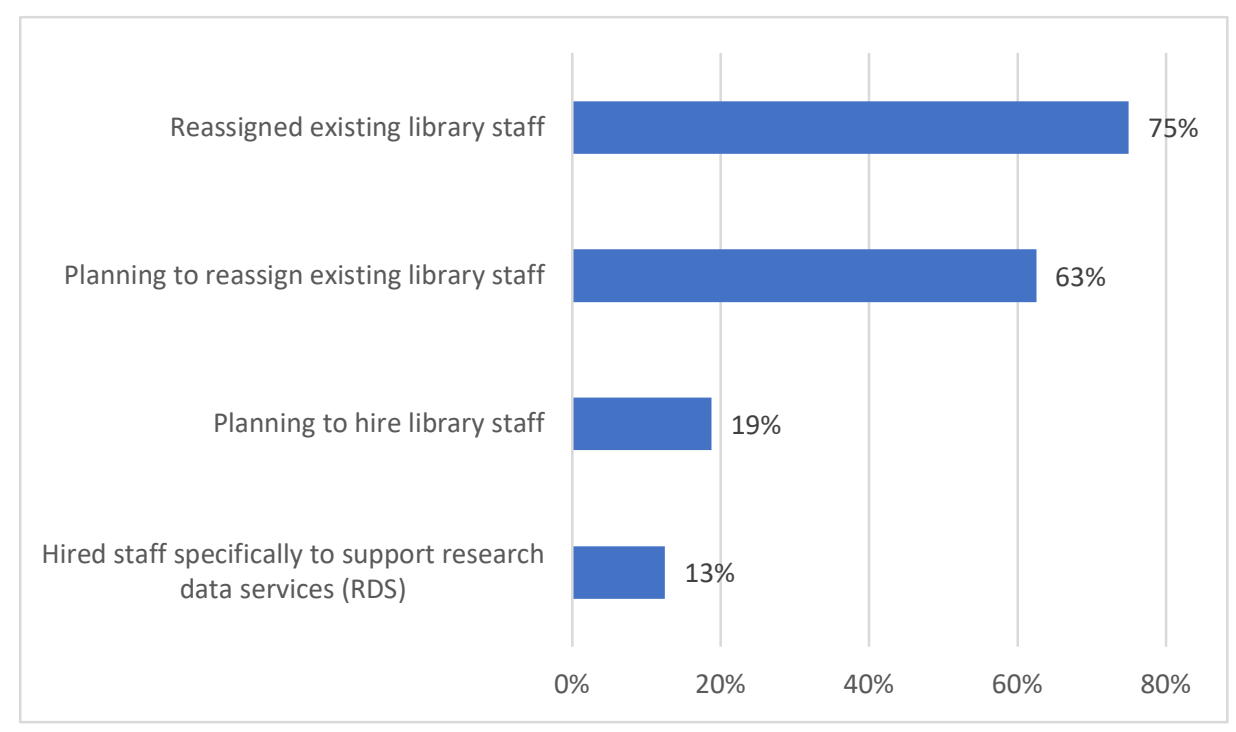

Figur 3. How has your library developed staff capacity for research data services (RDS)? (Check all that apply), n=27 (Rydving, 2019b).

Angående samarbete svarade i stort sett alla bibliotek (16 av 18 stycken, $89 \%$ ) att de samarbetar med någon annan avdelning inom den egna institution om forskningsstödjande tjänster för forskningsdata. Forskningsadministrativ avdelning är den föredragna partnern, men många samarbetar också med IT-avdelningen. Ungefär hälften av biblioteken har samarbeten utanför institutionen, främst med andra universitet eller statliga organ. Undersökningen visar också att humaniora är det ämnesområde där biblioteken i högst grad anger att de är delaktiga i forskarnas och studenternas verksamhet med forskningsstödjande tjänster för forskningsdata. Ingenjörs- och IT-miljöer har liten grad av inblandning från biblioteken.

Det är i huvudsak en positiv inställning till forskningsstödjande tjänster för forskningsdata bland biblioteksledare. Figur 4 visar att av de 18 bibliotek som svarat är $78 \%$ 
starkt, eller till dels eniga i att biblioteket behöver erbjuda forskningsstödjande tjänster för forskningsdata för att säkra sin relevans vid egen institution. Likaså anser en majoritet (79 \%) att det vill vara en nackdel för forskarmiljöerna om inte biblioteket erbjuder forskningsdatatjänster. Det markeras också enighet vad gäller viktigheten av att biblioteken intar en roll som "steward" för alla typer av kunskap, också datasett. De flesta menar att institutionen kan mista anseende om den inte har kontroll på egna data. Den största tveksamheten gäller i vilken grad det krävs ett engagemang i forskningsdatatjänster för att upprätthålla bibliotekets ekonomiska tilldelning. Det är de bibliotek som erbjuder flest tjänster inom fältet, som också anser att det är mest relevant.

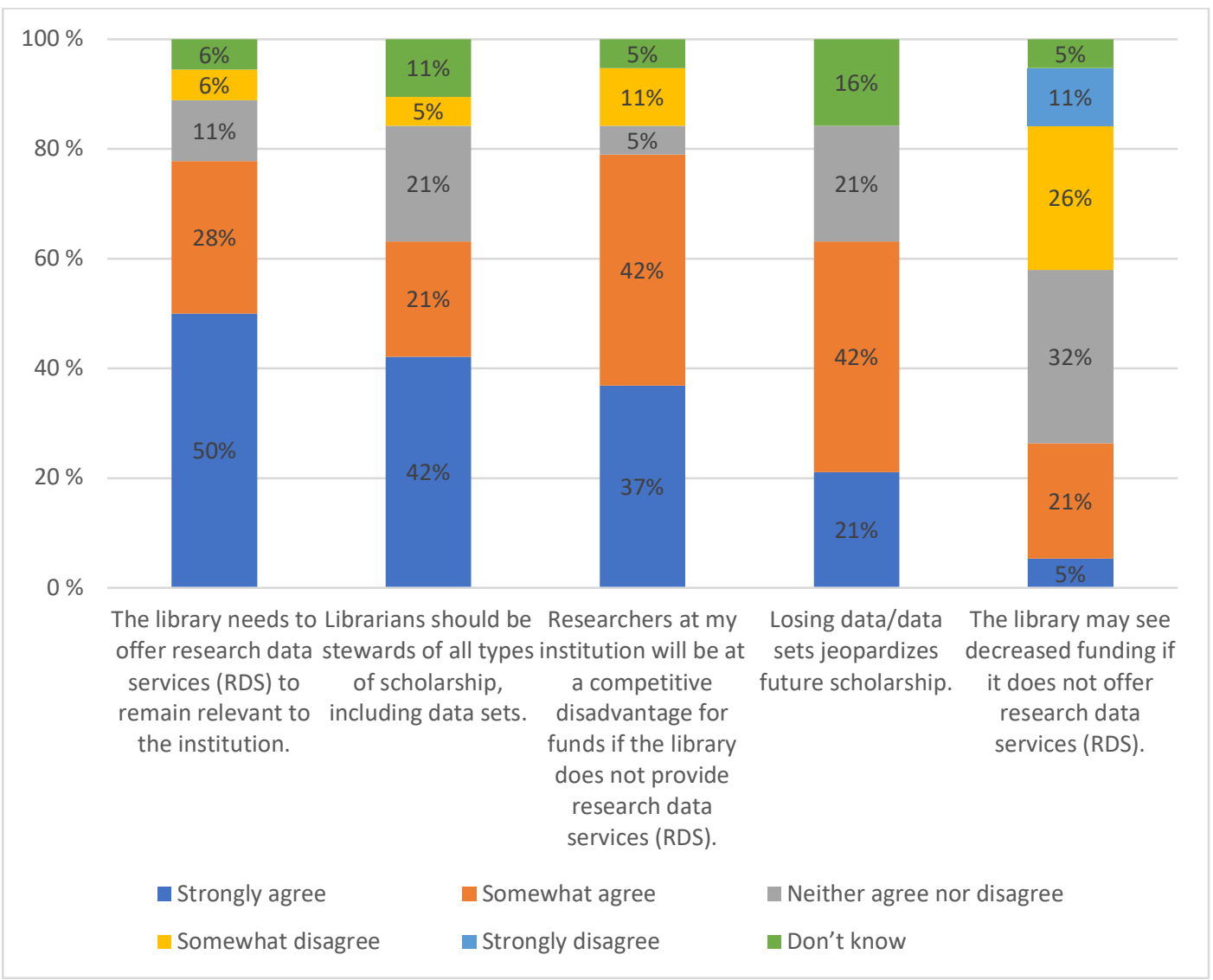

Figur 4. The following group of statements relates to your opinion on library involvement in research data services (RDS), $\mathrm{n}=93$ (Rydving, 2019a).

\section{Diskussion}

UH-bibliotek erbjuder främst rådgivande "mjuka" tjänster, men också teknikintensiva tjänster. Deltagande i arbete med policyutveckling eller strategisk planering rörande forskningsdatatjänster är den vanligast förekommande aktiviteten. Det kan tyda på att biblioteken här ser en nisch att agera inom, eller att moderinstitutionen ber om tjänsten. En tolkning kan vara att de tydliga forskningspolitiska riktlinjer som Norge har stimulerar till fokus på enskilda tjänster. Viljan att etablera tjänster för stöd till datahanteringsplaner kan ses i förlängningen av regeringens och finansiärers krav. 
Det är inte oväntat att biblioteken vid lärosätena med flest studenter, och därmed större ämnesmiljöer, både är de som erbjuder flest tjänster, och som har de mest ambitiösa planerna. De biblioteken kommer nog sannolikt att ta en ledande roll i fortsatt tjänsteutveckling. En otydlig uppdrags- och ansvarsfördelning inom institutionen kan utgöra ett hinder för biblioteken att utveckla tjänster inom fältet, vilket kan leda till ett avvaktande tillstånd. Lärosätets sammansättning av ämnesdiscipliner kan också påverka efterfrågan av forskningsstödjande tjänster för forskningsdata. Samarbete mellan institutioner spelar också in, liksom vilken roll andra aktörer tilläggs inom UH-sektorn, som t. ex. Unit ${ }^{1}$. Ekonomi är ytterligare en central faktor, där föringar i UH-sektorns budget sätter ramarna.

Resultatet visar att ett flertal av de svarande biblioteken har omfördelat sin personalstyrka, eller planerar att göra det, för att hantera forskningsstödjande tjänster för forskningsdata. Det tyder på att tema om ansvarsfördelning och kompetensutveckling är aktuella frågeställningar. Bibliotekspersonalens kunskap om, och intresse för, forskningsdatatjänster är av största vikt för att styrka utbudet. Knapphet på tid kan vara ett hinder för att utveckla de mer integrerade tjänsterna med ämnesmiljöerna. Deltagelse i forskningsprojekt och praktisk datahantering kan också vara mer tidkrävande än rådgivning.

En majoritet av biblioteksledarna erkänner forskningsdatatjänster som ett betydelsefullt område för bibliotekets utveckling. Det kan tolkas som att forskningsdatatjänster uppfattas som ett strategiskt område för att styrka bibliotekets legitimitet. Biblioteksledarna kan utöva hög grad av strategiskt inflytande bl. a. genom tydliggörande av samarbetspartner, utvecklings- och ansvarsområden, och vilka eventuella nya rekryteringar som sker. Biblioteksledarnas vilja att bejaka kompetenshävande aktiviteter är naturlig, då svaren i första hand pekar på att det är befintlig personal som ska täcka kompetensbehovet för att utöva tjänsterna. Ett fokus på existerande personal vill kanske inte heller kräva större ingrepp i ekonomin, och ligger i linje med de förväntningar som hör till arbetsgivarens ansvar.

UH-biblioteken uttrycker en hög grad av samarbetsvilja. Det indikerar att biblioteksledarna uppfattar forskningsdatafältet som omfattande. Samverkan med andra aktörer, såväl inom som utanför den egna institutionen, kan vara en metod för att skapa kraftfulla forskningsstödjande tjänster för forskningsdata. Avgörande för att lyckas med tjänsterna vill dock vara att få förtroende hos användarna. Det vill därför vara förmånsenligt att biblioteket har strategier för att söka upp och involvera sina användare i tjänsteutveckling.

Figur 5 beskriver en modell för samarbetande kompetensprofiler för forskningsstödjande tjänster för forskningsdata vid en institution. Min utgångspunkt är att biblioteket har en central funktion, i samarbete med andra avdelningar som IT-, och forskningsadministrativ avdelning. Modellen beskriver samarbetsgränssnitt inom biblioteket, och med andra avdelningar och ämnesområden. Kompetensprofilerna kan innehas av olika typer av bibliotekarier, men också rådgivarfunktioner kan vara aktuella. Ett intresse för IKT är

\footnotetext{
${ }^{1}$ Unit. https://www.unit.no/
} 
grundläggande. Huruvida tjänsteområdet täcks av en person, eller flera, är beroende av t. ex. efterfrågan på tjänsterna, tillgång på personal, och satsning från biblioteksleder och lärosätet.

Det är viktigt att erbjuda en tydlig och okomplicerad väg för forskare att ta kontakt för information och frågor. Denna frontfunktion 1) kan hanteras av någon som har god, generell kompetens och intresse för fältet så att användarens behov kan identifieras. Den andra kompetensprofilen 2) rymmer kunskap om olika filformat, metadata, licens- och upphovsrätt och officiella riktlinjer. Den funktionen kan ha en nära koppling till IT, men också intresse för juridik är relevant. Det tredje kompetensprofilen 3) kräver forskningskompetens och med fördel ämnesspecifik kunskap om det aktuella ämnesområdet. Här kan också kunskap om visualisering och dataanalyser vara relevant.

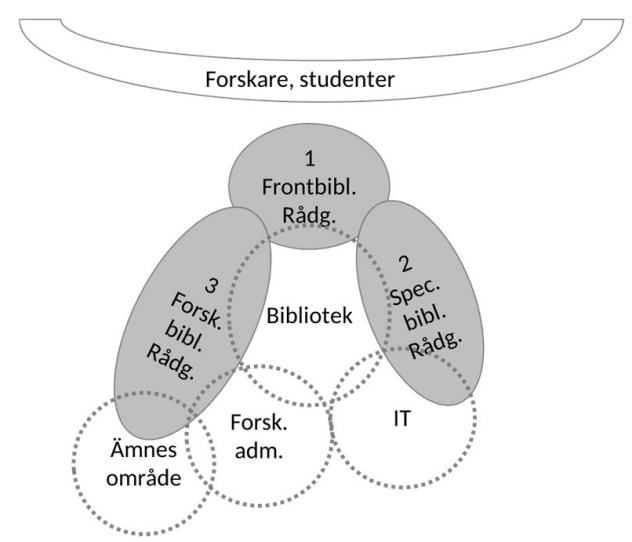

Figur 5. Samarbetande kompetensprofiler för forskningsstödjande tjänster för forskningsdata. (Rydving, 2019a).

Dessa funktioner innehåller lite, eller inte något, traditionellt biblioteksarbete. De som arbetar inom dessa funktioner rör sig gärna i skärningspunkten mellan olika avdelningar och utforskar på olika sätt hur biblioteket kan stödja forskningen.

\section{Avslutning}

I denna artikel har jag kort presenterat status och planer för forskningsstödjande tjänster för forskningsdata i UH-bibliotek. Tjänsteområdet framstår som etablerat vid de flesta bibliotek och det finns en ambition om fortsatt växt. Det är vanligare med rådgivande tjänster än tekniskt orienterade, både vad gäller dagens utbud och vidare planer. Angående hur kompetensutveckling och samarbete hanteras visar undersökningen att befintlig personal i första hand förväntas möta efterfrågan, och att samarbetsviljan genomgående är hög. Biblioteksledarna indikerar att de uppfattar forskningsdatatjänster som väsentliga för bibliotekets utveckling. Jag har också presenterat några kompetensprofiler som kan vara användbara för att utöva forskningsdatatjänster.

Hur ett ökande engagemang i forskningsdatafältet påverkar bibliotekarierollen blir intressant att följa. Det kan vara aktuellt att undersöka hur de som faktiskt utför arbetsuppgifter 
inom området upplever sin arbetssituation. Ett annat tema att studera kan vara hur utvecklingen av forskningsdatatjänster påverkar bibliotekets ställning inom den egna institutionen. Den avgörande partnern är dock forskaren. En bättre kunskap om forskares förväntningar och behov vill därför vara värdefullt för vidare arbete.

\section{Litteratur}

Corrall, S. (2012). Roles and responsibiliteis: libraries, librarians and data. I Pryor, G. (Red.), Managing Research Data (s. 105-133). London: Facet Publishing.

Cox, A. M., Pinfield, S. \& Smith, J. (2014). Moving a brick building: UK libraries coping with research data management as a 'wicked' problem. Journal of Librarianship and Information Science, 48(1), 3-17. https://doi.org/10.1177/0961000614533717

Forskningsrådet. (2017). Tilgjengeliggjøring av forskningsdata: Policy for Norges forskningsråd. Oslo: Forskningsrådet. Retrieved from https://www.forskningsradet.no/contentassets/e4cd6d2c23cf49d4989bb10c5eea087a/p olicy-for-apen-tilgang-til-forskningsdata.pdf

Forskningsrådet. (2020). Forskningsrådets policy om åpen forskning. Oslo: Forskningsrådet. Retrieved from https://www.forskningsradet.no/contentassets/98222e889c004c108a83bb4d32816779/ policy-apen-forskning.pdf

Frank, E. \& Pharo, N. (2016). Academic Librarians in Data Information Literacy Instruction: A Case Study in Meteorology. College \& Research Libraries, 77(4), 536-552. https://doi.org/10.5860/crl.77.4.536

Fransson, J., du Toit, M., Tapia Lagunas, P. \& Kjellberg, S. (2016). Tillgängliggörande av forskningsdata : nulägesbeskrivning samt rekommendationer för uppbyggnad av stöd till högskolans forskare. Malmö högskola. https://doi.org/10.24834/2043/20266

Johannessen, A., Tufte, P.-A. \& Christoffersen, L. (2016). Introduksjon til samfunnsvitenskapelig metode (5. utg.). Oslo: Abstrakt.

Kunnskapsdepartementet. (2017). Nasjonal strategi for tilgjengeliggjøring og deling av forskningsdata. Retrieved from https://www.regjeringen.no/contentassets/3a0ceeaa1c9b4611a1b86fc5616abde7/no/pd f/f-4442-b-nasjonal-strategi.pdf

Lewis, M. (2010). Libraries and the management of research data. I McKnight, S. (Red.), Envisioning Future Academic Library Services (s. 145-168). London: Facet Publishing.

Linde, P., Noorman, M., Wessels, B. \& Sveinsdottir, T. (2014). How can libraries and other academic stakeholders engage in making data open? Information Services and Use, 34(3/4), 211-219. doi.org/10.3233/ISU-140741

Rydving, K. (2019a). En studie om forskningsstödjande tjänster för forskningsdata. (Mastergradsavhandling). OsloMet-storbyuniversitet, Oslo.

Rydving, K. (2019b). Research Data Services in Norwegian Academic Research Libraries. I Landøy, A., Ghinucolov. S., Repanovici, A. (Red.), International Trends in Academic Library Development (s. 98-110). Chisinau: Cartdidact. https://zenodo.org/record/3524992

Strasser, C. \& Krier, L. (2014). Data Management for Libraries : A LITA Guide. New York: American Library Association. 
Tenopir, C., Birch, B. \& Allard, S. (2012). Academic libraries and research data services. Current Practices and Plans for the Future. Chicago: Association of College and Research Libraries.

Tenopir, C., Sandusky, R. J., Allard, S. \& Birch, B. (2013). Academic librarians and research data services: preparation and attitudes. IFLA journal, 39(1), 70-78.

Tenopir, C., Hughes, D., Allard, S., Frame, M., Birch, B., Baird, L., ... Lundeen, A. (2015). Research data services in academic libraries: Data intensive roles for the future? Journal of eScience Librarianship, 4(2), 1-23. http://dx.doi.org/10.7191/jeslib.2015.1085

Tenopir, C., Talja, S., Horstmann, W., Late, E., Hughes, D., Pollock, D., ... Allard, S. (2017). Research Data Services in European Academic Research Libraries. LIBER Quarterly. 27(1), 23-44. http://doi.org/10.18352/lq.10180

Wilson, J. A., Martinez-Uribe, L., Fraser, M. A. \& Jeffreys, P. (2011). An Institutional Approach to Developing Research Data Management Infrastructure. IJDC, 6(2), 274287. 